\title{
INFLUENCE OF DRUGS ON EVOKED POTENTIALS IN THE CAT CEREBELLUM: III. EFFECTS OF MORPHINE HYDROCHLORIDE (2)
}

\author{
Yukiko SUZUKI and Kyoji TAGUCHI \\ Department of Pharmacology. Showa College of Pharmaceutical Science, \\ Tsurumaki, Setagaya-ku, Tokvo 154, Japan
}

Accepted February 23, 1983

\begin{abstract}
In intact cats, morphine hydrochloride $(2.0 \mathrm{mg} / \mathrm{kg}, i . v$.) depressed spontaneous discharge of the Purkinje cell in 8 of the 15 neurons tested. These effects of morphine were antagonized by naloxone hydrochloride $(0.4 \mathrm{mg} / \mathrm{kg}$, i.v.). This opiate significantly decreased the evoked potentials produced by superficial radial nerve (SR) stimulation in the molecular layer of the cerebellar cortex. Although morphine decreased the potentials evoked by SR or tooth pulp stimulation in the nucleus fastigii and nucleus interpositus, this drug hardly influenced them in the nucleus dentatus. In the decerebrated cats, morphine significantly increased the potentials evoked in the cerebellar cortices by SR stimulation. In the somatosensory area I (SSA-1) - or motor area (MA)-lesioned cats, morphine decreased the cerebellar potentials evoked by SR stimulation, but increased them in the SSA-I- and MA-lesioned cats. Naloxone antagonized these effects of morphine. From our results, it appears that the decreasing effects of morphine on the cerebellar potentials evoked by SR stimulation may be affected by the functions of the SSA-I and MA of the cerebral cortex and that morphine may influence the cerebellum.
\end{abstract}

Numerous studies on the effects of morphine on the central nervous system have been made to pharmacologically determine the mechanism of action of morphine to cause analgesia, emotional change and tolerance, etc. (1-4).

With regard to pharmacological studies with the cerebellum, the effects of nembutal (5), diphenylhydantoin (6), and amphe tamine (7) on the Purkinje cells of the cerebellum have been reported. We have reported previously that CNS depressants and stimulants affected the cerebellar afferent pathways, probably in an indirect manner (8). and that morphine depressed the potentials evoked in the cerebellar cortex by superficial radial nerve (SR) stimulation (9).

In our present work, in order to study in detail the action of morphine on the cere- bellum, we investigated the influence of morphine on spontaneous spike discharge of the Purkinje cell, on the evoked potentials produced by SR stimulation in the molecular layer of the cerebellar cortex. and on the evoked potentials produced by SR or by tooth pulp stimulation in three cerebellar nuclei. Furthermore, for the purpose of investigating these morphine-induced decreasing actions at the neuronal level, we also studied the effects of morphine on the evoked potentials in the cerebellar cortex using decerebrated cats and somatosensory area 1 - or motor area-lesioned cats.

\section{Materials and Methods}

Fifty-seven adult cats $(2.5-4.3 \mathrm{~kg})$ of either sex were fixed on a stereotaxic instrument (Narishige type) after anesthetization 
with ether, and a tracheal cannula was inserted. Decerebrated cats were prepared by transection between the superior and inferior colliculi. The motor area (MA) - or the somatosensory area I (SSA-I)-lesioned cats were made by the aspiration of the MA or SSA-I of the cerebra! cortex. The femoral vein was cannulated for the injection of drugs. The superficial radial nerve (SR) of the forelimb was dissected and cut at its peripheral end. The central part of the nerve end was placed on bipolar stimulating electrodes with a $2 \mathrm{~mm}$ polar separation (platinum wires) and stimulated with rectangular pulses $(0.1 \mathrm{~Hz}, 30 \mathrm{~V}, 1 \mathrm{msec})$ in a pool of warm liquid paraffin. To record the evoked potentials and the spontaneous discharge of the Purkinje cell, a part of the occipital bone was removed to expose the vermis which was then covered with a pool of warm liquid paraffin to prevent drying and to keep the temperature between $37-38^{\circ} \mathrm{C}$. Evoked potentials in the molecular layer of the cerebellar cortex and the spontaneous discharge of the Purkinje cell were recorded from the vermis (lobules VI and VII) (10) of the cerebellar cortex with single-barrel glass microelectrodes filled with $3 \mathrm{M}-\mathrm{KCl}$ (resistance of 5-10 Mohm). The Purkinje cell discharge was identified by anatomical location and by the unit response to antidromic stimulation of the white matter or the nucleus olivaris inferior (11). When the stable spontaneous discharges of the Purkinje cell were maintained for 5-10 $\mathrm{min}$ after microelectrode insertion, the cell was judged not to be injured by electrode impalement. Stainless steel concentric electrodes with a diameter of $0.6 \mathrm{~mm}$ (tip separation $0.5 \mathrm{~mm}$ ) were inserted stereotaxically in order to record evoked potentials in the cerebellar nuclei. The recording portions were the nucleus fastigii (FN: P, 9.0; L, 1.5; H, +1.0), nucleus interpositus (IN: P. 9.0; L, 5.O; H, +0.5 ), and nucleus dentatus (DN: P. 9.0;
$\mathrm{L}, 7.0 ; \mathrm{H},-0.5)$, according to the atlas of Snider and Niemer (12). A small hole was drilled into the dentine of the lower canine tooth, bipolar stainless steel electrodes $(0.6$ $\mathrm{mm}$ diameter, tip separation $0.5 \mathrm{~mm}$ ) were inserted, and the electrode was covered with dental cement. The tooth pulp was stimulated electrically $(0.1 \mathrm{~Hz}, 0.5 \mathrm{msec}, 40-50 \mathrm{~V})$. After the recovery from ether, the cats were artificially respired (25 revolutions per minute) and immobilized with gallamine triethiodide (5-10 $\mathrm{mg} / \mathrm{kg}$, i.v.). End-tidal $\mathrm{CO}_{2}$ was maintained at $4.0-4.5 \%$. Body temperature, monitored by a rectal probe, was maintained at $37-38^{\circ} \mathrm{C}$ with a heating pad. Arterial blood pressure, ECG, $\mathrm{Hb}$ and $\mathrm{O}_{2}$ saturation were recorded throughout the experiments. At the termination of an experiment, $0.3 \mathrm{~mA}$ direct current was passed for $10 \mathrm{sec}$ through the electrodes from which evoked potentials had been recorded. The cerebellum was removed and fixed in 10\% formalin and then sectioned serially at $50 \mathrm{\mu m}$ to histologically verify the area of the electrode insertion. A stimulator (Model ME 6022, MEC) was used for the $S R$ and tooth pulp stimulations. The evoked potentials were displayed on an oscilloscope (Model 311. San-ei, Instrument Co.. Ltd.) and were averaged by a signal processor (Model 7T07. San-ei, Instrument Co., Ltd.). Averaged signals were recorded on a $X-Y$ recorder (Model WX 422, Watanabe). Evoked potentials are averaged for those obtained by 20 repetitive stimuli. Action potentials of the Purkinje cell were amplified by conventional means and monitored on an oscilloscope; and then they were coverted to a constant voltage pulse with a window discriminator for frequency counting. For recording spontaneous activity, the window discriminator output was also led to a computor (a signal processor) to construct pulse density variation histograms. The amplitude of the evoked potentials were measured from the baseline 
to the peak of a negative or positive wave. Peak time, which was the time from the stimuli to the peak of the negative or positive component, was measured. The drugs used in these studies were morphine hydrochloride (Sankyo) and naloxone hydrochloride (Endo Laboratories). Drugs for injection were dissolved in $0.9 \%$ saline.

The statistical significance of the data obtained was assessed using the two-tailed Student's t-test.

\section{Results}

The dose of morphine hydrochloride used in the present study was $2.0 \mathrm{mg} / \mathrm{kg}$. which had been found to decrease the cerebellar cortical potentials evoked by the stimulation of the SR by about $50 \%$ in the previous study (9).

1. Effects of morphine on spontaneous discharge of the cerebellar Purkinje cells in the intact cat: The spontaneous activities of 15 Purkinje neurons were obtained extracellularly in the vermal regions of lobules $V I$ and VII, discharge rates being 20-48 spikes/sec (mean $31 \pm 15$ (S.E.M.) spikes/ sec). As shown in Fig. 1, morphine $(2.0$ $\mathrm{mg} / \mathrm{kg}$. i.v.) decreased the Purkinje cell spontaneous discharge by $64.2 \pm 11 \%$ (mean \pm S.E.M.) at $1 \mathrm{~min}$ in 8 of 15 neurons tested. Discharge rate partially returned to the control level 90-120 min after morphine administration. This inhibition by morphine was antagonized by naloxone hydrochloride $(0.4 \mathrm{mg} / \mathrm{kg}$, i.v.). Blood pressure was only slightly depressed during infusion, and there occurred a rapid recovery ( $<3 \mathrm{~min}$ ) to pre-drugs levels on removal of the drug. On the other hand, in 4 of the 15 neurons tested. morphine caused increases in the spontaneous activity of Purkinje neurons by $34.8 \pm 10.5 \%$ at $5 \mathrm{~min}$. This excitatory effect of morphine was also antagonized by naloxone at $15 \mathrm{~min}$. In 3 of the neurons tested, morphine had no effect on the Purkinje cell spontaneous discharge.

2. Effects of morphine on evoked potentials in the cerebellar cortex (molecular layer in the vermal lobules $\mathrm{V} I$ and $\mathrm{VII}$ ) produced by SR stimulation in the intact cat: The potential recorded at a depth of $300-400 \mu \mathrm{m}$ in the cerebellar cortex consisted mainly of a positive component, thus being in a mirror image relation to that recorded from the cerebellar surface. The peak time of the positive potential was $25.0 \pm 8.6 \mathrm{msec}(n=5)$,

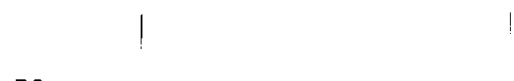

PC:
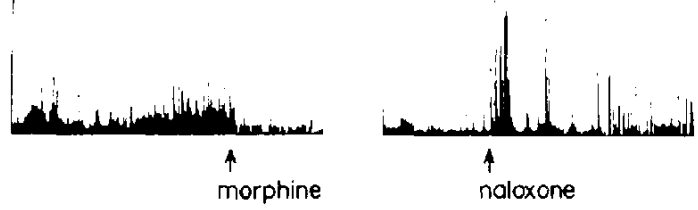

$P C_{2}$
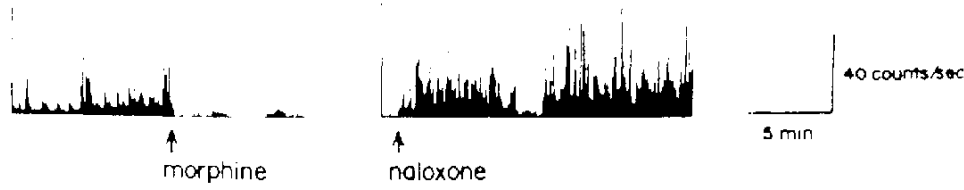

Fig. 1. Effect of morphine hydrochloride $(2.0 \mathrm{mg} / \mathrm{kg}$, i.v. $)$ on the spontaneous discharge of the Purkinje cells and antagonism by naloxone hydrochloride $(0.4 \mathrm{mg} / \mathrm{kg}$. i.v. $)$. The pulse density variation histograms obtained from two different Purkinje cells $\left(P C_{1}\right.$ and $\left.P C_{2}\right)$. Naloxone was administered at 15 min after morphine. 
A
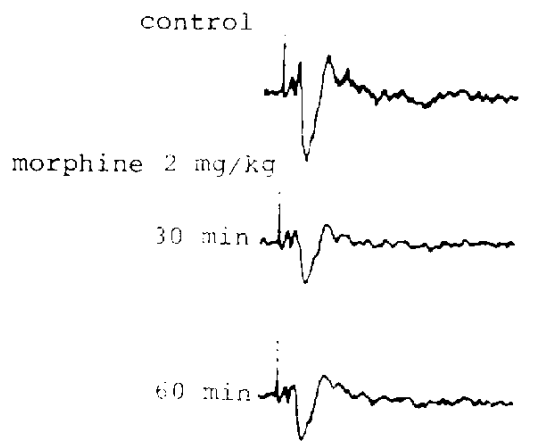

naloxone $0.4 \mathrm{mg} / \mathrm{kg}$

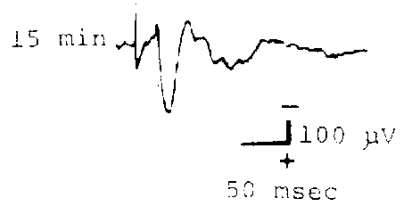

control

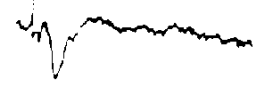

norphine $2 \mathrm{mg} / \mathrm{kg}$
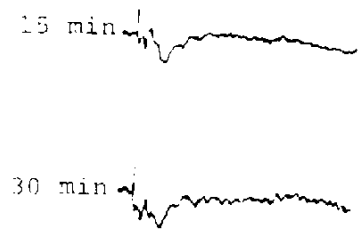

naloxone $0.4 \mathrm{mg} / \mathrm{kg}$

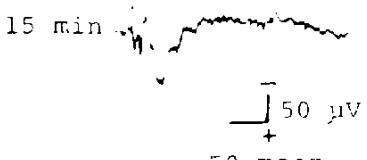

$50 \mathrm{msec}$

Fig. 2. Effects of morphine hydrochloride $(2.0 \mathrm{mg} / \mathrm{kg}$. i. . $)$ and naloxone hydrochloride $(0.4 \mathrm{mg} / \mathrm{kg}$, i.v. $)$ on the evoked potentials produced by superficial radial nerve stimulation in the cat cerebellar cortex (molecular layer: $300-400 \mu \mathrm{m}$ ) (A) and in the nucleus fastigii of the cat cerebellum (B). Naloxone was administered at $65 \mathrm{~min}(A)$ and $35 \mathrm{~min}$ (B) after morphine. Potentials illustrated are the averages of 20 responses for each.

Table 1. Effects of morphine hydrochloride $(2.0 \mathrm{mg} / \mathrm{kg}$, i.v. $)$ on the evoked potentials produced by superficial radial nerve stimulation in the vermis

\begin{tabular}{|c|c|c|c|c|c|}
\hline & \multirow[b]{2}{*}{ Components } & \multirow{2}{*}{ Control } & \multicolumn{2}{|c|}{$\begin{array}{l}\text { Amplitude }(\mu V) \text { of the } \\
\text { evoked potentials }\end{array}$} & \multirow[b]{2}{*}{ Naloxone } \\
\hline & & & Morphine & $\%$ change & \\
\hline \multirow[t]{2}{*}{ Intact } & $N$ & - & - & - & 一 \\
\hline & P & $231 \pm 17$ & $124 \pm 12^{* *}$ & -47 & $211 \pm 15 t \dagger$ \\
\hline \multirow[t]{2}{*}{ Decerebrate } & $N$ & $189 \pm 14$ & $289 \pm 20^{* *}$ & +53 & $191 \pm 10^{t \dagger}$ \\
\hline & $\mathrm{P}$ & $120 \pm 168$ & $167 \pm 22^{*}$ & +39 & $133 \pm 14^{\dagger}$ \\
\hline \multirow{2}{*}{$\begin{array}{l}\text { MA and SSA-1 } \\
\text { lesions }\end{array}$} & N & $106 \pm 12$ & $161 \pm 20^{* *}$ & +51 & $116 \pm 9^{1 \dagger}$ \\
\hline & $P$ & $131 \pm 128$ & $183 \pm 23^{* *}$ & +39 & $122 \pm 12^{\dagger}$ \\
\hline \multirow[t]{2}{*}{ MA lesion } & N & $124 \pm 16$ & $86 \pm 21^{*}$ & -31 & $114=11^{\dagger}$ \\
\hline & $\mathrm{P}$ & $106 \pm 19 \S$ & $74 \pm 23^{*}$ & -31 & $101=8^{\dagger}$ \\
\hline \multirow[t]{2}{*}{ SSA-I lesion } & $N$ & $119 \pm 15$ & $76 \pm 17^{*}$ & -37 & $110 \pm 15 t$ \\
\hline & P & $109 \pm 18 \$$ & $84 \pm 15$ & -24 & $104 \pm 11$ \\
\hline
\end{tabular}

Each value is shown as the mean \pm S.E.M. of 5 animals. Significant difference from the control value: *P<0.05. " $P<0.01$. Significant difference from "30 min after morphine": $+P<0.05$. * $+\$<0.01$. Significant difference from the control amplitude in the intac: cat: $\$ \mathrm{P}<0.001$. Naloxone was administrated i.v. $35 \mathrm{~min}$ after morphine. MA: motor area, SSA-I: somatosensory area 1. N: negative, P: positive, + : increase. - : decrease. 
and the amplitude was $231 \pm 17 \mu \mathrm{V}(n=5)$ (Fig. 2A and Table 1). Morphine maximally decreased, at 15-30 min, the amplitude of the evoked potentials by $47 \%$ without affecting the peak time; and this depressing action of morphine on the amplitude was antagonized by naloxone (Table 1 and Fig. 2A).

3. Effects of morphine on the evoked potentials in the cerebellar nuclei produced by SR stimulation in the intact cat: The evoked potentials consisting of the negative and positive components were produced by SR stimulation (Fig. 2B and Table 2). The peak times of the negative component were $16.9 \pm 2.7 \mathrm{msec}$ in the FN. $20.7 \pm 6.9 \mathrm{msec}$ in the DN, and $19.7 \pm 4.0 \mathrm{msec}$ in the $I \mathrm{~N}$; and peak times of the positive component were $41.7 \pm 12.9 \mathrm{msec}$ in the $\mathrm{FN}$ and $37.5 \pm 8.5$ msec in the DN. Morphine maximally decreased the amplitudes of both negative and positive components, by $45 \%$ and $44 \%$. respectively, in the $\mathrm{FN}$, and decreased the negative component by $24 \%$ in the $I N$, at
15 min: but both negative and positive components in the DN were not significantly affected by morphine (Fig. $2 \mathrm{~B}$ and Table 2). Recovery was seen after 150-180 min. Such remarkable decreasing actions of morphine on the amplitude in the $\mathrm{FN}$ and $\mathrm{IN}$ were antagonized by naloxone (Fig. $2 \mathrm{~B}$ and Table 2).

4. Effects of morphine on the evoked potentials produced in the cerebellar nuclei by tooth pulp stimulation in the intact cat: The evoked potentials produced in the FN and $\mathrm{IN}$ by tooth pulp stimulation possessed a negative component alone. The peak time was $21.5 \pm 6.0 \mathrm{msec}$ and the amplitude was $36.4 \pm 9.1 \mu \mathrm{N}$ in the $\mathrm{FN}$ and the peak time was $20.3=3.4 \mathrm{msec}$ and the amplitude was $41.6 \pm 8.1 \mathrm{HV}$ in the IN (Table 2). Tooth pulp stimulation evoked the potentials with the negative and positive components in the DN, whose peak times were $16.0 \pm 4.5 \mathrm{msec}$ and $40.8 \pm 7.8 \mathrm{msec}$, respectively: and their amplitudes were $15.4 \pm 3.9 \mu \mathrm{V}$ and $13.3 \pm 6.0$ $\mu V$, respectively (Table 2 ). As shown in

Table 2. Effects of morphine hydrochloride $(2.0 \mathrm{mg} / \mathrm{kg}$, i.v.) on the amplitude $(\mu \mathrm{V})$ of the evoked potentials produced by superficial radial nerve or tooth pulp stimulation in the FN, IN, and DN

\begin{tabular}{|c|c|c|c|c|c|c|}
\hline $\begin{array}{l}\text { Stimulating } \\
\text { sites }\end{array}$ & $\begin{array}{l}\text { Recording } \\
\text { sites }\end{array}$ & $\begin{array}{l}\text { Compo- } \\
\text { nents }\end{array}$ & Control & Morphine & $\%$ change & Naloxone \\
\hline & FN & $N$ & $28 \pm S$ & $15 \pm 7^{* *}$ & -45 & $26 \pm 4^{\dagger}$ \\
\hline & & P & $49 \pm 4$ & $28 \pm 9^{* *}$ & -44 & $43 \pm 7+$ \\
\hline \multirow[t]{6}{*}{$S R$} & IN & $N$ & $65 \pm 7$ & $50 \pm 9^{*}$ & -24 & $61 \pm 5 t$ \\
\hline & & $P$ & - & - & - & - \\
\hline & DN & N & $36 \pm 9$ & $30 \pm 9$ & -18 & $32 \pm 7$ \\
\hline & & $P$ & $30 \pm 8$ & $23 \pm 8$ & -24 & $23 \pm 9$ \\
\hline & FN & N & $36 \pm 9$ & $20 \pm 6^{* *}$ & -45 & $34 \pm 5^{\dagger}$ \\
\hline & & P & - & - & - & - \\
\hline \multirow[t]{4}{*}{ Tooth pulp } & IN & N & $42 \pm 8$ & $32 \pm 6^{*}$ & -25 & $40 \pm 6^{\dagger}$ \\
\hline & & $P$ & - & - & - & - \\
\hline & DN & $N$ & $15 \pm 4$ & $13 \pm 4$ & -19 & $12 \pm 6$ \\
\hline & & P & $13 \pm 6$ & $12 \pm 3$ & -8 & $12 \pm 7$ \\
\hline
\end{tabular}

Each value is shown as the mean \pm S.E.M. of 5 animals. Significant difference from the control value: *P<0.05, " $P<0.01$. Significant difference from "30 min after morphine": $t P<0.05$. Naloxone was administered i.v. $35 \mathrm{~min}$ after morphine. SR: superficial radial nerve, FN: nucleus fastigii, IN: nucleus interpositus, DN: nucleus dentatus, N: negative, P: positive, - : decrease, 
Table 2, morphine maximally produced a significant decrease of the amplitude of the evoked potentials in $15 \mathrm{~min}$, which was by $45 \%$ in the $F N$ and by $25 \%$ in the IN. These remarkable inhibitory actions of morphine in the $\mathrm{FN}$ and $\mathrm{IN}$ were antagonized by naloxone.

5. (a) Effects of morphine on the evoked potentials produced by SR stimulation on the cerebellar cortex in the decerebrated cat: As shown in Table 1, the evoked potentials on the vermal posterior labe of the decerebrated cat produced by SR stimulation possessed both negative and positive components which had peak times of $22.5 \pm 6.8$ msec and $46.9 \pm 7.9 \mathrm{msec}$ and amplitudes of $189.2 \pm 14 \mu \mathrm{V}$ and $120.2 \pm 16.2 \mu \mathrm{V}$. respectively. The control amplitude of the positive component in the decerebrated cat showed a significant difference $(P<0.001)$ in comparison with that in the intact cat. Morphine maximally produced a significant increase at $30 \mathrm{~min}$ in the amplitude of both negative and positive components by $53 \%$ and $39 \%$, respectively (Table 1). The increasing action of morphine was antagonized by naloxone.

5. (b) Effects of morphine on the evoked potentials produced by SR stimulation on the cerebellar cortex in the MA- or SSA-1lesioned cat: As shown in Fig. 3 and Table 1. the evoked potentials produced by $S R$ stimulation possessed both negative and positive components which had peak times of $24.5 \pm 4.1 \mathrm{msec}$ and $44.3 \pm 6.1 \mathrm{msec}$ respectively, on the vermal posterior lobe in the cerebellar cortex. Amplitudes of the negative and positive components were $124 \pm 16 \mu \mathrm{V}$ and $106 \pm 19 \mu \mathrm{V}$ in the MAlesioned cat, respectively, and $119 \pm 15 \mu \mathrm{V}$ and $109 \pm 18 \mu \mathrm{V}$ in the SSA-I-lesioned cat, respectively. The control amplitude of the positive component in the MA- or SSA-Ilesioned cat showed a significant difference $(P<0.001)$ in comparison with that in the intact cat. Morphine maximally decreased at 15 min the amplitude of both negative and positive components by $31 \%$ each at the MA lesion and by $37 \%$ and $24 \%$ at the SSA-1 lesion, respectively. There was no significant
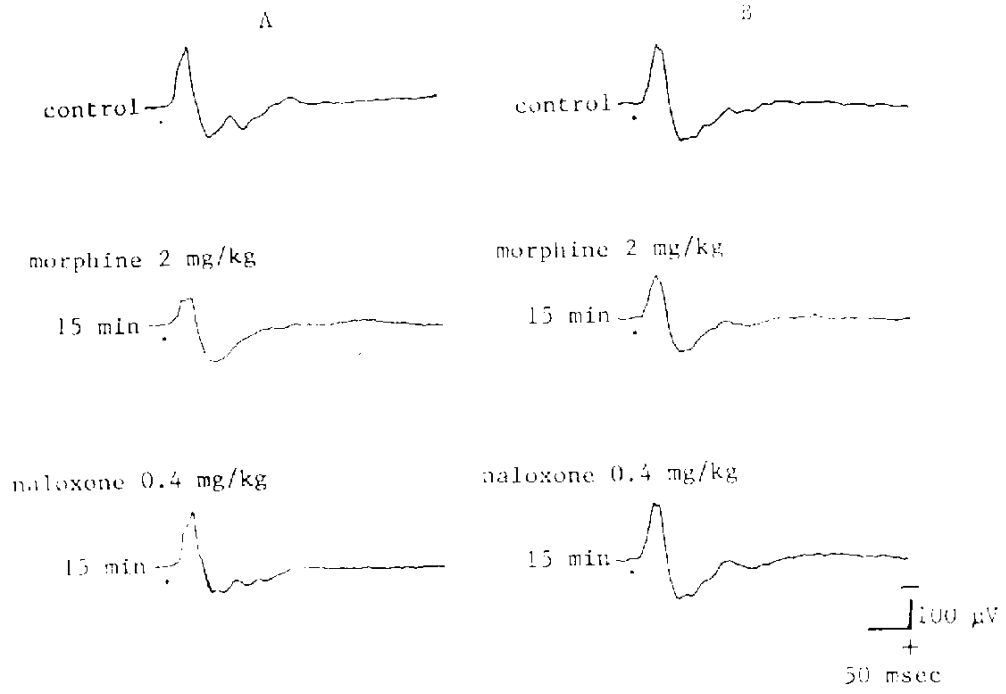

Fig. 3. Effects of morphine hydrochioride $(2.0 \mathrm{mg} / \mathrm{kg}$. i.v.) and naloxone hydrochloride $(0.4 \mathrm{mg} / \mathrm{kg}$. i.v.) on the evoked potentials produced by superficial radial nerve stimulation on the cerebellar cortex at the moter area-lesioned $(A)$ and somatosensory area l-lesioned (B) cats. Naloxone was administered at 20 min after morphine. Potentials illustrated are the averages of 20 responses for each. The timing of the stimulus is indicated by dots. 

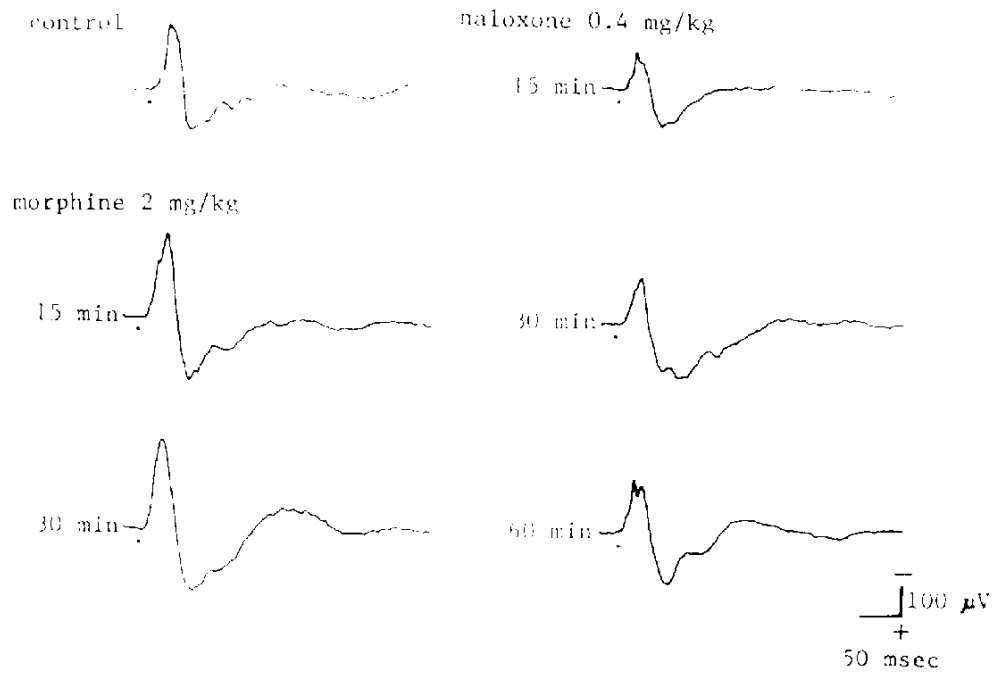

Fig. 4. Effects of morphine hydrochloride $(2.0 \mathrm{mg} / \mathrm{kg}$. i.v.) and naloxone hydrochloride $(0.4 \mathrm{mg} / \mathrm{kg}$. i.v.) on the evoked potentials produced by superficial radial nerve stimulation on the cerebellar cortex of the motor area- and the somatosensory area !-lesioned cat. Naloxone was administered at 35 min after morphine. Potentials illustrated are the averages of 20 responses for each. The timing of the stimulus is indicated by dots.

difference between the MA-lesioned cat and the SSA-I-lesioned cat in morphine-induced depression of the evoked potentials. These effects of morphine were antagonized by naloxone.

5. (c) Effects of morphine on the evoked potentials produced by $S R$ stimulation on the cerebellar cortex in the SSA-I- and MAlesioned cat: The evoked potentials produced by SR stimulation possessed both negative and positive components (Fig. 4 and Table 1) which had peak times of $24.8 \pm 5.9 \mathrm{msec}$ and $41.5 \pm 7.1 \mathrm{msec}$, respectively, and amplitudes of $106.3 \pm 12.1 \mu \mathrm{V}$ and $131.5 \pm 12.1$ $\mu \mathrm{V}$. respectively, on the vermal posterior lobe in the SSA-1- and MA-lesioned cats. The control amplitude of the positive component in the SSA-I- and MA-lesioned cat showed a significant difference $(P<0.001)$ in comparison with that in the intact cat. Morphine maximally increased at $30 \mathrm{~min}$ the amplitude of both components by $51 \%$ and $39 \%$. respectively (Table 1 ). The increasing action of morphine was antagonized by naloxone
(Table 1 and Fig. 4).

\section{Discussion}

Concerning the inputs from the peripheral nerve to the cerebellum, the group la, Ib. II. and III fibers from muscle and skin would be carrying touch, stretch, pressure, the guard hair follicles, or nociceptive information (1315). We previously reported that morphine depressed the cerebellar afferent pathways (9).

Eccles et al. $(16,17)$ reported that the climbing fiber responses were produced by the superficial radial nerve (SR) stimulation in the cat cerebellar cortex, and that the response from the molecular layer was the mirror image of that from the granular layer. suggesting that the climbing fiber responses may reflect the activation of adjacent Purkinje cell bodies. In our present studies, morphine decreased significantly the amplitude of the positive component of the evoked potentials (Fig. 2) and the Purkinje cell spontaneous discharge as well (Fig. 1). Thus, in support 
of the previous finding (9) that morphine depressed the inputs from the periphery to the Purkinje cells in the cerebellar cortex, the motor mechanism of the cerebellum was suggested to be influenced directly and indirectly by morphine.

With regard to the analgesic mechanism of morphine. Satoh et al. (3) and Dickenson et al. (1) reported that morphine affected the descending inhibitory system: and LeBars et al. (18) demonstrated that $2 \mathrm{mg} / \mathrm{kg}$ of morphine did not influence the responses of the $A \alpha$ fiber in the dorsal horn lamina $V$ type to peripheral nerve stimulation, but did reduce the responses of $A \delta$ and $C$ fibers by $40 \%$ and $70 \%$, respectively. Furthermore. Yaksh and Rudy $(2,19)$ reported that a local application of morphine in the subarachnoid space produced analgesia in rats, suggesting a direct inhibitory action on the spinal cord. In the present studies, morphine increased the cerebellar evoked potentials produced by peripheral nerve stimulation in the decerebrated cat. Thus, concerning the pathways from the periphery to the cerebellum. morphine-induced depression in intact cats can not be explained based on morphineinduced direct facilitation of the function of the descending inhibitory system (1,3) and of that of the spinal cord $(2,19)$. Therefore, pertaining to the effects of morphine on the pathways from the periphery to the cerebellum, another mechanism of action must be presumed

It has been reprted that the cerebellum communicates with the somatosensory area ! (SSA-1) and the motor area (MA) of the cerebrum (20-22). Thus, the cerebral cortex, in particular SSA-I and MA, may at least partly modulate the action of morphine on the potentials evoked in the cerebellar cortex by the peripheral nerve stimulation in the intact cat. Then, we tried to destroy the SSA-1 and MA in order to study minute influences of the these regions on the cerebellum. Morphine, however, depressed the evoked potentials produced in the cerebellar cortex by the peripheral nerve stimulation in the SSA-I- or MA-lesioned cat, while this opiate increased them in the SSA-1and MA-lesioned cat. Therefore, interaction between the function of SSA-1 and that of MA may influence the action of morphine. The control amplitude of the positive component of the potentials evoked by SR stimulation in the SSA-1- and MA-lesioned cats' cerebellum was significantly lower than that in the intact cat, but the control amplitude in the SSA-1- and MA-lesioned cat showed no significant difference in comparison with that in the SSA-1- or MA-lesioned cat (Table 1). Thus, the neuronal functions of the MA and SSA-I may be to facilitate the pathways from SR to the cerebellum, and it was suggested that morphine-induced decreasing actions of the potentials evoked by SR stimulation in the intact cat cerebellar cortex were due to the inhibition of the MAand SSA-I-induced facilitation.

In the cerebellar nuclei. morphine significantly depressed the $I N$ - and FN-evoked potentials produced by peripheral nerve or tooth pulp stimulation, but did not influence the evoked potentials in the DN (Table 2). Doba (23) reported that electrical stimulation of the ventral medial part of the FN produced grooming and predatory attack behavior and suggested the functional localization to be in the cerebellar nuclei. It was suggested by the present result that the cerebellar nuclei may possess functional localization because the evoked potentials in the $F N$ and IN, but not DN, were depressed by morphine.

The fact that morphine enhanced the inputs from the periphery to the cerebellar cortex in the SSA-1- and MA-lesioned cats may not be directly related to the analgesic mechanism. It is conceivable, however, that morphine may influence functions of the cerebellum in motor and postural adjustments 
by modulating these cerebro-cerebellar pathways.

In conclusion, it was suggested that morphine depressed the inputs to the cerebellum. The functions of SSA-1 and MA of the cerebral cortex may play an important role in the inhibitory action of morphine on the evoked potentials in the cerebellum.

Acknowledgments: We are grateful to colleagues in our laboratory for pertinent discussion and excellent technical assistance.

\section{References}

1) Dickenson, A.H., Oliveras, J.L. and Besson, J.M.: Role of the nucleus raphe magnus in opiate analgesia as studied by the microinjection technique in the rat. Brain Res. 170 . 95-111 (1979)

2) Yaksh, T.L. and Rudy, T.A.: Analgesia mediated by a direct spinal action of narcotics. Science 192, 1357-1358 (1976)

3) Satoh, M. and Takagi, H.: Enhancement by morphine of the central descending inhibitory influence on spinal sensory transmission. Eur. J. Pharmacol. 14, 60-65 (1971)

4) Johnson, S.M. and Duggan, A.W.: Tolerance and dependence of dorsal horn neurones of the cat; The role of the opiate receptors of the substantia gelatinosa. Neuropharmacology 20 , 1033-1038 (1981)

5) Van Gilder, J.C. and O'Leary, J.L.: Effect of nembutal anesthesia upon Purkinje cell activation in the cat. Electroencephalogr. Clin. Neurophysiol. 30, 173-188 (1971)

6) Julien, R.M. and Halpern, L.M.: Effects of diphenylhydantoin and other antiepileptic drugs on epileptiform activity and Purkinje cell discharge rates. Epilepsia (Amst.) 13, 387-400 (1972)

7) Freedman, R. and Marwaha, J.: Effects of acute and chronic amphetamine treatment on Purkinje neuron discharge in rat cerebellum. J. Pharmacol. Exp. Ther. 212, 390-396 (1979)

8) Suzuki, Y., Taguchi, K. and Hagiwara, Y. Influences of drugs on evoked potentials in the cat cerebellum: I. Effects of CNS depressants and stimulants on the cerebellar afferent pathways. Japan. J. Pharmacol. 32, 457-468 (1982)

9) Suzuki, Y., Hagiwara, Y., Taguchi, K. and Kajiyama, K.: Effect of morphine on cerebellar evoked responses in cats. Folia Pharmacol. Japon. 74, 163P (1978) (in Japanese)

10) Larsell, 0. : The cerebellum of the cat and monkey. J. Comp Neurol. 99, 135-199 (1953)

11) Eccles, J.C., Ito, $M$. and Szentagothi, J.: The Cerebellum as a Neuronal Machine. SpringerVerlag. Berlin-Heidelberg and New York (1967)

12) Snider, R.S. and Niemer, W.T.: A Stereotaxic Atlas of the Cat Brain. The University of Chicago Press, Chicago (1961)

13) Hunt, C.C. and Mclntyre, A.K.: An analysis of fibre diameter and receptor characteristics of myelinated cutaneous afferent fibres in cat. J. Physiol. (Lond.) 153, 99-112 (1960)

14) Paintal, A.S.: Functional analysis of group 111 afferent fibers of mammalian muscles. J. Physiol. (Lond.) 152, 250-270 (1960)

15) Burgess, P.R. and Perl, E.R.: Myelinated afferent fibers responding specifically to noxious stimulation of the skin. J. Physiol. (Lond.) 190, 541562 (1967)

16) Eccles, J.C., Provini, L., Strata, P. and Taborikova, H.: Analysis of electrical potentials evoked in the cerebellar anterior lobe by stimulation of hindlimb and forelimb nerves. Exp. Brain Res. 6, 171-194 (1968)

17) Eccles, J.C., Llinas, R. and Sasaki, K.: The excitatory synaptic action of climbing fibres on the Purkinje cells of the cerebellum. J. Physiol. (Lond.) 182, 268-296 (1966)

18) LeBars, D., Guibaud, G., Jurna, I. and Besson, J.M.: Differential effects of morphine on responses of dorsal lamina $V$ type cells elicited by $\mathrm{A}$ and $\mathrm{C}$ fibre stimulation in the spinal cat. Brain Res. 115, 518-524 (1976)

19) Yaksh, T.L. and Rudy, T.A.: Studies on the direct spinal action narcotics in the production of analgesia in the rat. J. Pharmacol. Exp. Ther. 202, 411-428 (1977)

20) Snider, R.S. and Eldred, E.: Electro-anatomica! studies on the cerebro-cerebellar connections in the cat. J. Comp. Neurol. 95, 1-16 (1951)

21) Allen, G.l., Azzena, G.B. and Ohno, T.: Responses of neurons of interpositus nucleus to stimulation of the sensorimotor cortex. Brain Res. 45, 585-589 (1972)

22) Brodal, A.: Cerebrocerebellar Pathways. Anatomical data and some functional implications. Acta Physiol. Scand. 51, Supp., 153-195 (1972)

23) Doba, N.: Orthostatic cardiovascular responses and attack behaviours elicited by electrical stimulation of the fastigil nucleus. Seitai no Kagaku 26, 408-419 (1975) (in Japanese) 